\title{
Organization of some repetitive DNAs and B chromosomes in the grasshopper Eumastusia koebelei koebelei (Rehn, 1909) (Orthoptera, Acrididae, Leptysminae)
}

\author{
Allison Anjos', Vilma Loreto², Diogo C. Cabral-de-Mello' \\ I Departamento de Biologia, Instituto de Biociências, UNESP, Rio Claro, São Paulo, CEP 13506-900, Brazil \\ 2 Departamento de Genética, Centro de Ciências Biológicas, UFPE, Recife, Pernambuco, 50732-970, Brazil \\ Corresponding author: Diogo C. Cabral-de-Mello (mellodc@rc.unesp.br) \\ Academic editor: V. Gokhman | Received 23 December 2015 | Accepted 3 March 2016 | Published 6 April 2016 \\ http://zoobank.org/CAE1C186-F575-46FB-B73E-E7C35B0745EC \\ Citation: Anjos A, Loreto V, Cabral-de-Mello DC (2016) Organization of some repetitive DNAs and B chromosomes \\ in the grasshopper Eumastusia koebelei koebelei (Rehn, 1909) (Orthoptera, Acrididae, Leptysminae). Comparative \\ Cytogenetics 10(2): 219-228. doi: 10.3897/CompCytogen.v10i2.7609
}

\begin{abstract}
B chromosomes occur in approximately $15 \%$ of eukaryotes and are usually heterochromatic and rich in repetitive DNAs. Here we describe characteristics of a B chromosome in the grasshopper Eumastusia koebelei koebelei (Rehn, 1909) through classical cytogenetic methods and mapping of some repetitive DNAs, including multigene families, telomeric repeats and a DNA fraction enriched with repetitive DNAs obtained from DOP-PCR. Eumastusia k. koebelei presented 2n=23, X0 and, in one individual, two copies of the same variant of a B chromosome were noticed, which are associated during meiosis. The C-positive blocks were located in the pericentromeric regions of the standard complement and along the entire length of the $\mathrm{B}$ chromosomes. Some $\mathrm{G}+\mathrm{C}$-rich heterochromatic blocks were noticed, including conspicuous blocks in the B chromosomes. The mapping of $18 \mathrm{~S}$ rDNA and U2 snDNA revealed only autosomal clusters, and the telomeric probe hybridized in terminal regions. Finally, the DOP-PCR probe obtained from an individual without a $\mathrm{B}$ chromosome revealed signals in the heterochromatic regions, including the entire length of the $\mathrm{B}$ chromosome. The possible intraspecific origin of the $\mathrm{B}$ chromosomes, due to the shared pool of repetitive DNAs between the A and B chromosomes and the possible consequences of their association are discussed.
\end{abstract}

\section{Keywords}

Cytogenetics, DOP-PCR, FISH, multigene family, Orthoptera

Copyright Allison Anjos et al. This is an open access article distributed under the terms of the Creative Commons Attribution License (CC BY 4.0), which permits unrestricted use, distribution, and reproduction in any medium, provided the original author and source are credited. 


\section{Introduction}

The grasshoppers of the subfamily Leptysminae (Orthoptera, Acrididae) are divided into two tribes, Leptysmini and Tetrataeniini, comprising 75 species distributed exclusively in the Neotropical region (Amedegnato 1974, Carbonell 1977, Roberts and Carbonell 1982). The genus Eumastusia (Rehn, 1909) belongs to Tetrataeniini, with one species and two subspecies recognized, E. koebelei koebelei (Rehn, 1909) and E. k. chapadendis Roberts \& Carbonell, 1980. For Leptysminae, few chromosomal data are available and, as in other Acrididae grasshoppers, most species exhibit the basic karyotype $2 \mathrm{n}=23, \mathrm{X} 0{ }^{\hat{n}}$ with acrotelocentric chromosomes (Mesa et al. 1982, Loreto and de Souza 2000, Rocha et al. 2004). However, derived karyotypes arising from diploid number reduction were reported in Stenopola pallida (Bruner, 1906), Leptysma argentina Bruner, 1906 and Tetrataenia surinama (Linnaeus, 1764) (Mesa et al. 1982, Bidau and Hasson 1984). Additionally, B chromosomes have been reported in some species (Bidau and Hasson 1984, Confalonieri and Bidau 1986, Rocha et al. 2004), but no studies using molecular cytogenetic approaches have been conducted to elucidate the origin and evolution of these chromosomes.

B chromosomes are present in approximately 15\% of eukaryote species and although discovered in 1907, they remain a mystery regarding their origin and evolution in most species (Houben et al. 2014). They are dispensable elements, largely known for their selfish nature as genomic parasites with patterns of non-Mendelian inheritance and a tendency to accumulate (Camacho 2005, Houben et al. 2014). These elements may arise from chromosomes of the carrier species or as a result of interspecific hybridization (Camacho et al. 2000), and they have their own evolutionary fate in different species and types of B chromosome (Banaei-Moghaddam et al. 2015). In some species, iso B chromosomes, formed by two identical arms, were described, which usually arise from centromere misdivision of telo- or acrocentric B chromosomes (see for example Grieco and Bidau 2000, Marques et al. 2012, Valente et al. 2014).

The accumulation of repetitive DNAs as an evolutionary process has been frequently reported for B chromosomes (Camacho 2005, Houben et al. 2014, BanaeiMoghaddam et al. 2015). These repetitive DNAs have been informative for understanding chromosomal and genomic evolution among grasshoppers (Cabrero and Camacho 2008, Cabrero et al. 2009, Cabral-de-Mello et al. 2011a, Anjos et al. 2015, Camacho et al. 2015, Palacios-Gimenez et al. 2015), as well as the possible evolutionary history of B chromosomes (Teruel et al. 2010, Oliveira et al. 2010, Bueno et al. 2013). To contribute to the understanding of chromosomal diversification, $B$ chromosome evolution and patterns of repetitive DNA organization in Leptysminae, a poorly studied group, we analyzed the chromosomes of the species Eumastusia koebelei koebelei (Acrididae, Leptysminae). The analyses were performed through conventional and differential chromosome staining and through fluorescent in situ hybridization (FISH) using distinct probes, such as $18 \mathrm{~S}$ rDNA, the TTAGG telomeric motif, U2 snDNA and a repetitive DNA fraction obtained by degenerate oligonucleotide-primed PCR (DOP-PCR). 


\section{Material and methods}

Ten adult males of E. k. koebelei were collected in Serrolândia/Pernambuco, Brazil. The testes were fixed in Carnoy's solution (3:1 absolute ethanol:acetic acid) and stored at $-20^{\circ} \mathrm{C}$ until use. For chromosomal preparations, the tissues were macerated in a drop of $50 \%$ acetic acid and the slides were dried using a hot plate at $40-45^{\circ} \mathrm{C}$. All individuals were studied using conventional staining with 5\% Giemsa to describe the general karyotype structure. C-banding was performed according to Sumner (1972) and fluorochrome staining $\left(\mathrm{CMA}_{3} / \mathrm{DA} / \mathrm{DAPI}\right)$ was performed according to Schweizer et al. (1983).

The $18 \mathrm{~S}$ ribosomal DNA (rDNA) sequence and the U2 snDNA were obtained through polymerase chain reaction (PCR) from the genomes of Dichotomius semisquamosus (Curtis, 1845) (Coleoptera, Scarabaeidae) and Abracris flavolineata (De Geer, 1773) (Orthoptera, Acrididae), respectively, using primers described by Cabralde-Mello et al. (2010) and Bueno et al. (2013). Telomeric probes were obtained by PCR using the complementary primers (TTAGG) ${ }_{5}$ and (CCTAA), following the protocol proposed by Ijdo et al. (1991). Genomic amplification preferential for the repetitive DNAs was performed through DOP-PCR using as template the DNA from an individual without B chromosomes (Telenius et al. 1992). The DOP primer (5' CCG ACT CGA GNN NNN NAT GTG G3') was used following the specifications described by Mazzuchelli and Martins (2009).

The $18 \mathrm{~S}$ rDNA probe and DOP-PCR product were labeled using biotin-14-dATP through nick translation (Invitrogen, San Diego, CA, USA), while the telomeric probe and U2 snDNA were labeled through PCR with digoxigenin-11-dUTP (Roche, Mannheim, Germany). Fluorescent in situ hybridization (FISH) was performed according to the protocol proposed by Pinkel et al. (1986) with modifications described by Cabral-de-Mello et al. (2010). Single or double-color FISH was performed with the distinct probes and at least $200 \mathrm{ng}$ of each probe was used. Probes labeled with biotin14-dATP were detected using streptavidin-Alexa Fluor 488 (Invitrogen), and probes labeled with digoxigenin-11-dUTP were detected using anti-digoxigenin-Rhodamine (Roche). All preparations were counterstained with 4',6-diamidino-2-phenylindole (DAPI) and mounted in Vectashield (Vector, Burlingame, CA, USA). Chromosomes and signals were observed using an Olympus BX61 epifluorescence microscope equipped with appropriate filters. Photographs were recorded with a DP70 cooled digital camera. The images were merged and optimized for brightness and contrast with Adobe Photoshop CS2.

\section{Results and discussion}

The karyotype of E. k. koebelei is in accordance with previous descriptions (Mesa and Fontanetti 1983), corresponding to the modal karyotype for grasshoppers (Hewitt 1979, Mesa et al. 1982), which consists of 23 acrotelocentric chromosomes and the 


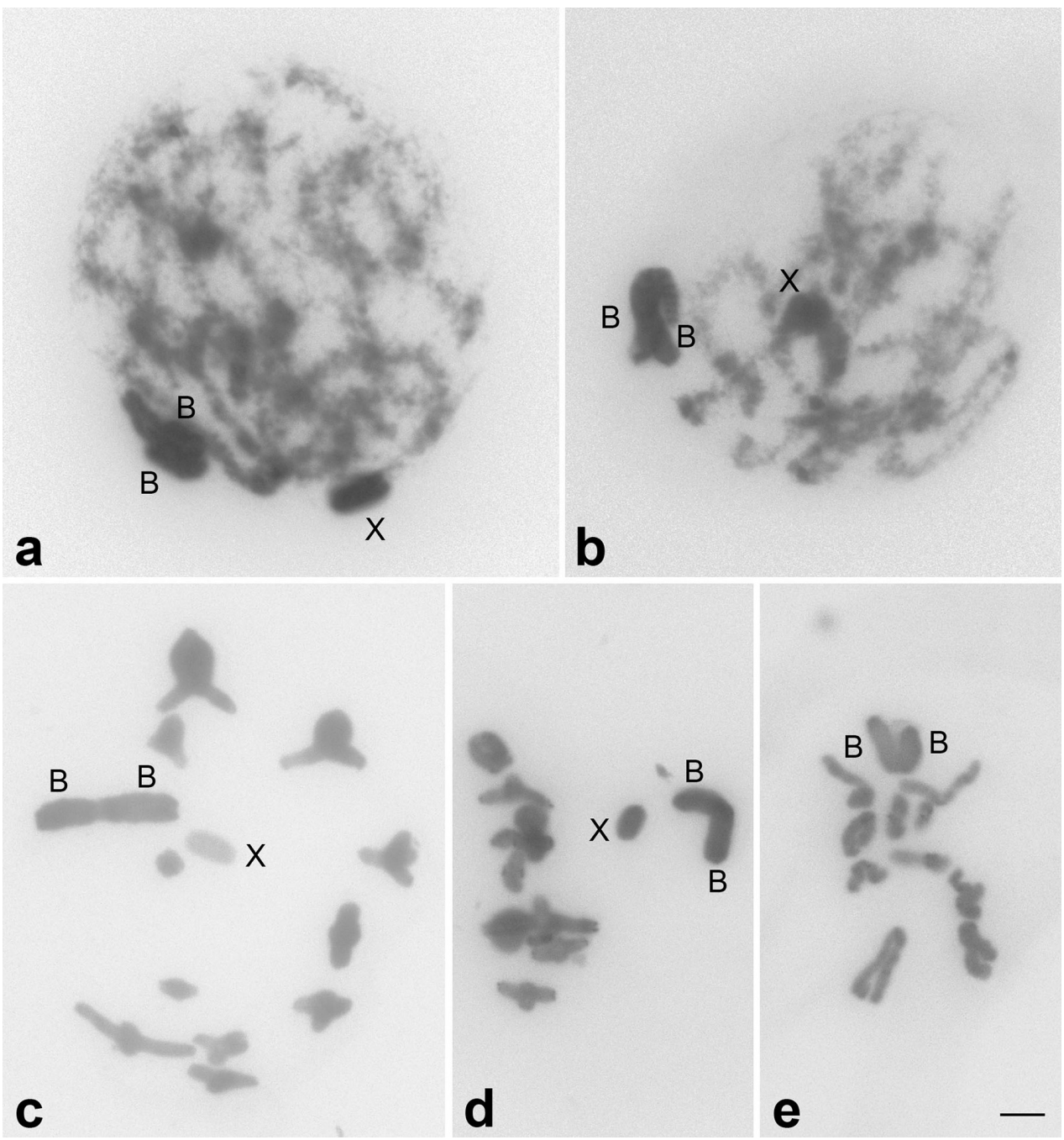

Figure I. Conventional staining with Giemsa in meiotic cells of E. k. koebelei harboring B chromosomes. $\mathbf{a}$ zygotene $\mathbf{b}$ early pachytene $\mathbf{c}$ metaphase I $\mathbf{d}$ anaphase I $\mathbf{e}$ metaphase II. B chromosomes are associated side by side in initial meiosis $(\mathbf{a}, \mathbf{b})$ and by centromere in other cells $(\mathbf{c}-\mathbf{e})$. These chromosomes are also segregated to the same pole in $\mathbf{d}$ and maintained together in metaphase II (e). X and B chromosomes are indicated. Bar: $5 \mu \mathrm{m}$.

X0 sex-determining system in males (Figure 1). This chromosomal pattern is also frequent in Leptysminae, occurring in 20 of 22 species studied (Mesa et al. 1982, Bidau and Hasson 1984, Confalonieri and Bidau 1986, Loreto and de Souza 2000, Rocha et al. 2004). Among the ten analyzed individuals, one carried two acrocentric $B$ chromosomes, which showed differential or similar condensation between them, depending on the cell analyzed (Figure 1). For the other Leptysminae, distinct variants of B chromosomes were previously observed in Stenopola dorsalis (Thunberg, 1827) (Rocha 
et al. 2004), Cylindrotettix obscurus (Thunberg, 1827) and C. santarosae Roberts, 1975 (Confalonieri and Bidau 1986). Throughout meiosis, the two B chromosomes were associated, including metaphase II (Figure 1). From initial meiosis to pachytene, the B chromosomes were associated side by side, apparently linked by the centromere (Figure 1a, b). After diplotene, these elements remained connected by centromeres (Figure 1ce), appearing as a single large biarmed chromosome under conventional analysis. These two B chromosomes segregate to the same pole during anaphase I (Figure 1d). This association suggests similarity between the two B chromosomes and that they could be two copies of the same B variant. Moreover, this association could influence the inheritance of these extra chromosomes, increasing the possibility of their segregation to the same anaphase pole, causing accumulation of these elements. In other grasshoppers, there are examples of acrocentric B chromosomes that are not associated throughout meiosis, such as in Rhammatocerus brasiliensis (Bruner, 1904) (Loreto et al. 2008).

C-banding revealed pericentromeric C-positive heterochromatic blocks in the A complement (Figure 2a), with the blocks in pairs 1, 2, 4-7, 9-11 and X chromosome being $\mathrm{G}+\mathrm{C}$-rich, while the rest of the heterochromatin was neutral for $\mathrm{CMA}_{3}$ or DAPI fluorochromes. The blocks in pairs 4 and 7 occurred in only one of the homologues. In pairs 3 and 5, terminal $\mathrm{CMA}_{3}^{+}$blocks were also noticed, being heteromorphic for pair 3 (Figure $2 \mathrm{~b}$ ). This pattern of $\mathrm{C}$-positive pericentromeric blocks associated with $\mathrm{CMA}_{3}^{+}$ heterochromatic blocks and/or heterochromatin without base specificity $(\mathrm{A}+\mathrm{T}$ or $\mathrm{G}+\mathrm{C})$ observed for the A chromosomes of E. $k$. koebelei is similar to other Leptysminae species, such as Cornops aquaticum (Bruner, 1906), Stenopola dorsalis, Stenacris xanthochlora (Marschall, 1836), Tucayaca parvula Roberts, 1977 and Belosacris coccineipes (Bruner, 1906), as well as in other species of Acrididae (Hewitt 1979, King and John 1980, Loreto and de Souza 2000, Rocha et al. 2004). In the two B chromosomes, the heterochromatin was distributed along their entire length (Figure $2 \mathrm{~d}$ ), and in the pericentromeric region a remarkable $\mathrm{CMA}^{3+}$ block was noticed. This $\mathrm{CMA}_{3}{ }^{+}$area appeared as a conspicuous block in metaphase I while in initial meiosis (pachytene), due to less condensation, dispersed dots were always observed side by side (Figure 2e, f) due to the association of the two B chromosomes. The shared $\mathrm{CMA}_{3}{ }^{+}$block in both $\mathrm{B}$ chromosomes reinforces their similarity, and we could speculate that a G+C-rich repetitive DNA, such as satellite DNA, could be present in the centromere of these $\mathrm{B}$ chromosomes, facilitating their constant association. This situation could cause a centromeric division failure that could favor the occurrence of whole-arm translocations leading to the formation of an isochromosome, proposed as a hypothesis for B isochromosome origin in the grasshopper Metaleptea brevicornis adspersa (Johannson, 1763) (Grieco and Bidau 2000).

Another argument favoring the notion of repetitive DNA enrichment in the Cpositive regions was confirmed through the use of the DOP-PCR fraction as a probe, which revealed strong signals in these areas (Figure 2c). This is also valid for the $\mathrm{B}$ chromosomes, which were completely labeled (Figure $2 \mathrm{~g}$ ). The enrichment of distinct classes of repetitive DNAs in B chromosomes is a common pattern and these sequences could be involved with B chromosome differentiation and evolution (Houben et al. 2014, Banaei-Moghaddam et al. 2015). Considering that the DOP-PCR probe was 


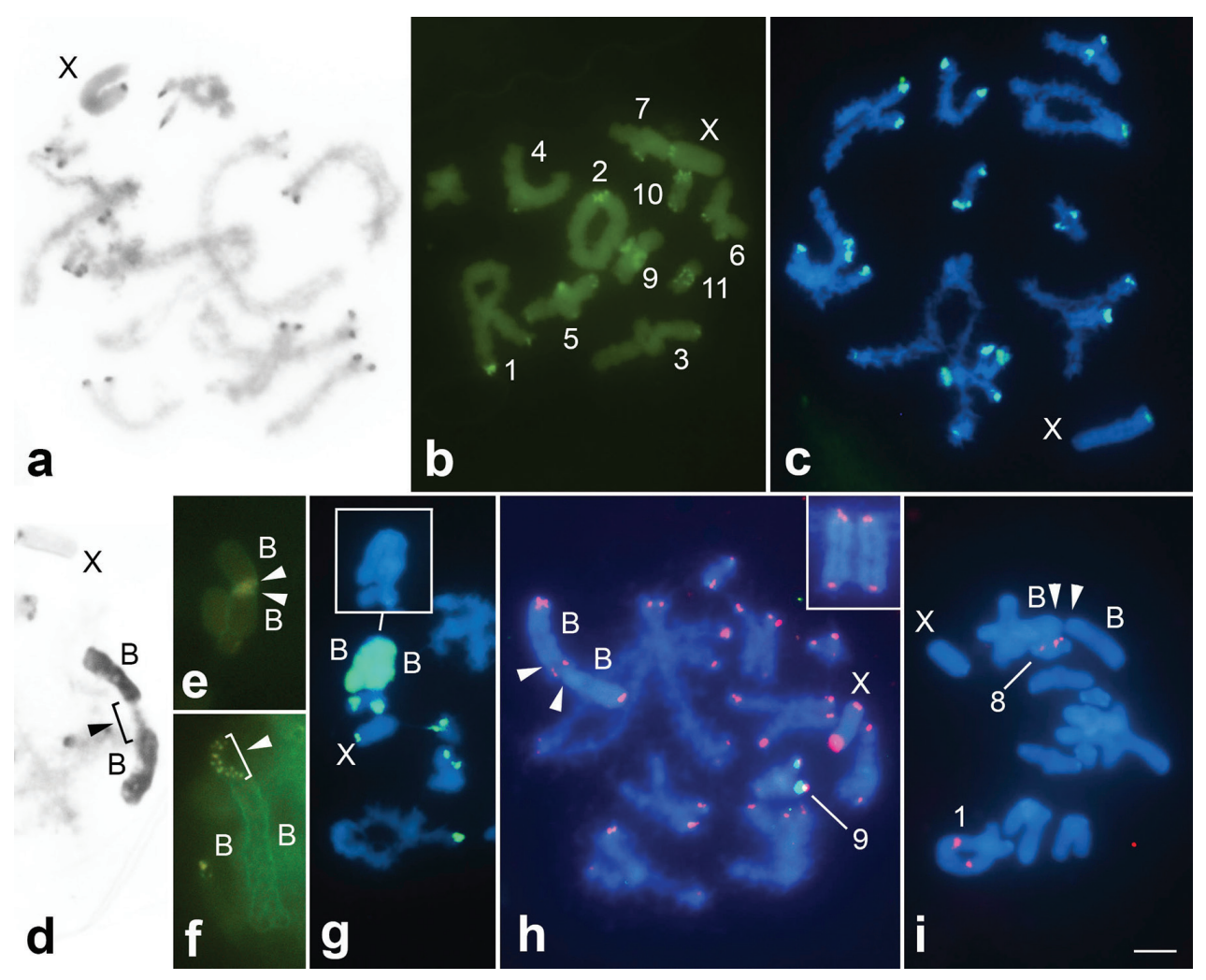

Figure 2. C-banding (a, d), CMA staining (b, e, f) and FISH using as probes DOP-PCR (c, g), $18 \mathrm{~S}$ rDNA-green and TTAGG-red (h) and U2 snDNA (i) in meiotic cells of E. k. koebelei with B chromosomes $(\mathbf{d}-\mathbf{i})$ and without them $(\mathbf{a}-\mathbf{c})$. $\mathbf{a}, \mathbf{h}$ late pachytene $\mathbf{b}$ early diakinesis $\mathbf{c}, \mathbf{d}, \mathbf{g}$ diplotene $\mathbf{e}, \mathbf{i}$ metaphase I $\mathbf{f}$ zygotene. Images $\mathbf{d}-\mathbf{g}$ partially highlight $\mathrm{B}$ chromosomes. X, B and other chromosomes harboring specific signals are indicated; arrowheads point to the centromeres of $\mathrm{B}$ chromosomes. Inserts in $\mathbf{g}, \mathbf{h}$ highlight $\mathrm{B}$ chromosomes. Bar: $5 \mu \mathrm{m}$.

obtained from an individual without $\mathrm{B}$ chromosomes, the repetitive DNA amplified using this approach is from the A genome. The hybridization signals in the B chromosomes indicate that this element shares repetitive sequences with the A complement, suggesting an intraspecific origin for the $\mathrm{B}$ chromosome. An intraspecific origin for $\mathrm{B}$ chromosomes was also suggested for other grasshoppers using distinct chromosomal markers, such as Abracris flavolineata (Menezes-de-Carvalho et al. 2015) and Locusta migratoria (Linnaeus, 1758) (Teruel et al. 2010), as well as other animal groups. Our result is similar to reports for the beetle Dichotomius geminatus (Arrow, 1913) using as probe the $C_{0} t-1 \mathrm{DNA}$ fraction that also isolates repetitive DNAs, such as the DOP-PCR, indicating the sharing of sequences between the $\mathrm{B}$ chromosome and the A complement (Cabral-de-Mello et al. 2011b). Although we suggest an intraspecific origin for the $\mathrm{B}$ chromosome in E. k. koebelei, it is impossible to determine if this event is related either to autosomes or the $\mathrm{X}$ chromosome, because both presented signals 
for the DOP-PCR probe and $\mathrm{CMA}_{3}^{+}$blocks. It is also impossible to define the specific type of shared sequence, as the DOP-PCR probe is anonymous.

FISH with the telomeric probe revealed terminal signals in all chromosomes, including the $\mathrm{B}$ chromosome (Figure $2 \mathrm{i}$ ). This result was expected considering that the karyotype of $E$. $k$. koebelei does not experienced gross chromosomal rearrangements observed in other Leptysminae, such as Stenopola pallida, Tetrataenia surinama and Leptysma argentina, bearing in mind the ancestral karyotype for grasshoppers (Mesa et al. 1982, Bidau and Hasson 1984). For the B chromosome, this probe confirmed that one individual harbored two B chromosomes (Figure 2i, insert) instead of one large biarmed chromosome, as suggested by conventional analysis. The mapping of multigene families revealed one pair of clusters on the same bivalent for $18 \mathrm{~S}$ rDNA, proximally in pair 9. For $\mathrm{U} 2$ snDNA, four clusters on two bivalents were noticed, with interstitial placement in pair 1 and 8 in decreasing order of size (Figure 2h, i). This multigene family and the U1 snDNA located in pair 3 (Anjos et al. 2015) were not observed in the $\mathrm{B}$ chromosomes (Figure $2 \mathrm{~h}, \mathrm{i}$ ). It is more parsimonious to consider that chromosomes $1,3,8$ and 9 were not involved in the origin of $\mathrm{B}$ chromosomes, but it could not be completely ruled out. Alternatively, these sequences could be lost during $\mathrm{B}$ chromosome differentiation, or the origin of the $\mathrm{B}$ chromosome did not involve the regions containing these sequences.

\section{Conflict of interest}

The authors declare that they have no conflict of interest.

\section{Acknowledgements}

This study was supported by Fundação de Amparo a Pesquisa do Estado de São PauloFAPESP (process number 2014/11763-8) and Coordenadoria de Aperfeiçoamento de Pessoal de Nivel Superior-CAPES. AA acknowledges scholarship obtained from FAPESP (process number 2014/06226-3). DCCM was recipient of a research productivity fellowship from Conselho Nacional de Desenvolvimento Científico e Tecnológico-CNPq (process number 304758/2014-0).

\section{References}

Amedegnato C (1974) Les genres d'acridiens néotropicaux, leur classification par familles, sousfamilles et tribus. Acrida 3: 193-204.

Anjos A, Ruiz-Ruano FJ, Camacho JPM, Loreto V, Cabrero J, Souza MJ, Cabral-de-Mello DC (2015) U1 snDNA clusters in grasshoppers: chromosomal dynamics and genomic organization. Heredity 114: 207-219. doi: 10.1038/hdy.2014.87 
Banaei-Moghaddam AM, Martis MM, Macas J, Gundlach H, Himmelbach A, Altschmied L, Mayer KF, Houben A (2015) Genes on B chromosomes: old questions revisited with new tools. Biochimica Biophysica Acta 1849: 64-70. doi: 10.1016/j.bbagrm.2014.11.007

Bidau CJ, Hasson ER (1984) Population cytology of Leptysma argentina Bruner (Leptysminae, Acrididae). Genetica 62: 161-175. doi: 10.1007/BF00056433

Bueno D, Palacios-Gimenez OM, Cabral-de-Mello DC (2013) Chromosomal Mapping of Repetitive DNAs in the Grasshopper Abracris flavolineata Reveal Possible Ancestry of the B Chromosome and H3 Histone Spreading. PLoS ONE 8: e66532. doi: 10.1371/journal. pone.0066532

Cabral-de-Mello DC, Cabrero J, López-León MD, Camacho JPM (2011a) Evolutionary dynamics of $5 \mathrm{~S}$ rDNA location in acridid grasshoppers and its relationship with $\mathrm{H} 3$ histone gene and 45S rDNA location. Genetica 139: 921-931. doi: 10.1007/s10709-011-9596-7

Cabral-de-Mello DC, Moura RC, Melo AS, Martins C (2011b) Evolutionary dynamics of heterochromatin in the genome of Dichotomius beetles based on chromosomal analysis. Genetica 139: 315-325. doi: 10.1007/s10709-011-9551-7

Cabral-de-Mello DC, Moura RC, Martins C (2010) Chromosomal mapping of repetitive DNAs in the beetle Dichotomius geminatus provides the first evidence for an association of $5 \mathrm{~S}$ rRNA and histone $\mathrm{H} 3$ genes in insects, and repetitive DNA similarity between the B chromosome and A complement. Heredity 104: 393-400. doi: 10.1038/hdy.2009.126

Cabrero J, Camacho JPM (2008) Location and expression of ribosomal RNA genes in grasshoppers: Abundance of silent and cryptic loci. Chromosome Research 16: 595-607. doi: 10.1007/s10577-008-1214-x

Cabrero J, López-León MD, Teruel M, Camacho JPM (2009) Chromosome mapping of H3 and $\mathrm{H} 4$ histone gene clusters in 35 species of acridid grasshoppers. Chromosome Research 17: 397-404. doi: 10.1007/s10577-009-9030-5

Camacho JP, Sharbel TF, Beukeboom LW (2000) B-chromosome evolution. Philosophical Transactions of the Royal Socety of London B 355: 163-178. doi: 10.1098/rstb.2000.0556 Camacho JPM (2005) B chromosomes. In: Gregory TR (Ed.) The Evolution of the Genome. Elsevier, 223-286. doi: 10.1016/b978-012301463-4/50006-1

Camacho JPM, Ruiz-Ruano FJ, Martín-Blázquez R, López-León MD, Cabrero J, Lorite P, Cabral-de-Mello DC, Bakkali M (2015) A step to the gigantic genome of the desert locust: chromosome sizes and repeated DNAs. Chromosoma 124: 263-275. doi: 10.1007/ s00412-014-0499-0

Carbonell CS (1977) Origin, evolution and distribution of the Neotropical Acridomorph fauna (Orthoptera): A preliminary hypothesis. Revista de la Sociedade Entomológica Argentina 36: 153-175.

Confalonieri VA, Bidau CJ (1986) The B-chromosomes of two species of Cylindrotettix (Leptysminae, Acrididae). Genetica 68: 87-95. doi: 10.1007/BF02424404

Grieco ML, Bidau CJ (2000) The dicentric nature of the metacentric B chromosome of Metaleptea brevicornis adspersa (Acridinae, acrididae). Heredity 84(6): 639-646. doi: 10.1046/j.1365-2540.2000.00688.x

Hewitt GM (1979) Grasshoppers and Crickets. Animal Cytogenetics. Vol. 3, Insecta 1, Orthoptera. Gebrüder Borntraeger, Berlin-Stuttgart, 170 pp. 
Houben A, Banaei-Moghaddam AM, Klemme S, Timmis JN (2014) Evolution and biology of supernumerary B chromosomes. Cellular and Molecular Life Sciences 71: 467-478. doi: 10.1007/s00018-013-1437-7

Ijdo JW, Wells RA, Baldini A, Reeders ST (1991) Improved telomere detection using a telomere repeat probe (TTAGGG) generated by PCR. Nucleic Acids Research 19: 4780. doi: $10.1093 /$ nar/19.17.4780

King M, John B (1980) Regularities and restrictions governing C-band variation in acridoid grasshoppers. Chromosoma 76: 123-150. doi: 10.1007/BF00293413

Loreto V, Cabrero J, López-León MD, Camacho JP, Souza MJ (2008) Possible autosomal origin of macro B chromosomes in two grasshopper species. Chromosome Research 16: 233-241. doi: 10.1007/s10577-007-1188-0

Loreto V, de Souza MJ (2000) Karyotype, constitutive heterochromatin and nucleolar organizer regions (NORs) in Belosacris coccineipes (Acrididae-Leptysminae). Genetics and Molecular Biology 23: 575-579. doi: 10.1590/S1415-47572000000300013

Marques A, Klemme S, Guerra M, Houben A (2012) Cytomolecular characterization of de novo formed rye B chromosome variants. Molecular Cytogenetics 5: 34. doi: 10.1186/1755-8166-5-34

Mazzuchelli J, Martins C (2009) Genomic organization of repetitive DNAs in the cichlid fish Astronotus ocellatus. Genetica 136: 461-469. doi: 10.1007/s10709-008-9346-7

Menezes-de-Carvalho NZ, Palacios-Gimenez OM, Milani D, Cabral-de-Mello DC (2015) High similarity of $\mathrm{U} 2$ snDNA sequence between A and B chromosomes in the grasshopper Abracris flavolineata. Molecular Genetics and Genomics 290: 1787-1792. doi: 10.1007/ s00438-015-1033-7

Mesa A, Ferreira A, Carbonell C (1982) Cariología de los Acridoideos Neotropicales: estado actual de su conocimiento y nuevas contribuciones. Annales de la Société Entomologique de France 18: 507-526.

Mesa A, Fontanetti CS (1983) Karyotypes of nine brazilian species of acridids (Orthoptera Acridoidea). Revista Brasileira de Genética 6: 295-305.

Oliveira SG, Moura RC, Silva AEB, Souza MJ (2010) Cytogenetic analysis of two Coprophanaeus species (Scarabaeidae) revealing wide constitutive heterochromatin variability and the largest number of $45 \mathrm{~S}$ rDNA sites among Coleoptera. Micron 41: 960-965. doi: 10.1016/j.micron.2010.06.015

Palacios-Gimenez OM, Marti DA, Cabral-de-Mello DC (2015) Neo-sex chromosomes of Ronderosia bergi: insight into the evolution of sex chromosomes in grasshoppers. Chromosoma 124: 353-365. doi: 10.1007/s00412-015-0505-1

Pinkel D, Straume T, Gray JW (1986) Cytogenetic analysis using quantitative, high-sensitivity, fluorescence hybridization. Proceedings of the National Academy of Sciences of the United States of America 83: 2934-2938. doi: 10.1073/pnas.83.9.2934

Roberts HR, Carbonell CS (1982) A revision of the grasshopper genera Chromacris and Xestotrachelus (Orthoptera, Romaleidae, Romaleinae). Proceedings of the California Academy of Sciences 43: 43-58.

Rocha MDF, Souza MJ, Moura RC (2004) Karyotypic analysis, constitutive heterochromatin and NOR distribution in five grasshopper species of the subfamily Leptysminae (Acrididae). Caryologia 57: 107-116. doi: 10.1080/00087114.2004.10589378 
Schweizer D, Mendelak M, White MJD, Contreras N (1983) Cytogenetics of the parthenogenetic grasshopper Warramaba virgo and its bisexual relatives. Chromosoma 88: 227-236. doi: 10.1007/BF00285625

Sumner AT (1972) A simple technique for demonstrating centromeric heterochromatin. Experimental Cell Research 75: 304-306. doi: 10.1016/0014-4827(72)90558-7

Telenius H, Pelmear AH, Tunnacliffe A, Carter NP, Behmel A, Ferguson-Smith MA, Nordenskjöld M, Pfragner R, Ponder BA (1992) Cytogenetic analysis by chromosome painting using DOP-PCR amplified flow-sorted chromosomes. Genes Chromosomes Cancer 4: 257-263. doi: 10.1002/gcc.2870040311

Teruel M, Cabrero J, Perfectti F, Camacho JPM (2010) B chromosome ancestry revealed by histone genes in the migratory locust. Chromosoma 119: 217-225. doi: 10.1007/s00412009-0251-3

Valente GT, Conte MA, Fantinatti BEA, Cabral-de-Mello DC, Carvalho RF, Vicari MR, Kocher TD, Martns C (2014) Origin and evolution of B chromosomes in the cichlid fish Astatotilapia latifasciata based on integrated genomic analyses. Molecular Biology and Evolution 31: 2061-2072. doi: 10.1093/molbev/msu148 